\title{
The Effects of Emotional Marketing on Consumer Product Perception, Brand Awareness and Purchase Decision - A Study in Ho Chi Minh City, Vietnam
}

\author{
Mai Ngoc Khuong and Vu Ngoc Bich Tram
}

\begin{abstract}
This study was conducted to identify the impacts of emotional marketing on purchase decision. Quantitative approach was the major method used and a self-administered questionnaire survey was conducted with sample size of 197 consumers who used the products of OMO washing powder, Neptune oil, Kotex tampon, and Red Bear noodle. The results showed that all factors of emotional marketing were positively associated with consumers' purchase decision. In addition, this study argues that, in order to achieve high level of consumers' purchase decision, companies employing emotional marketing should; a) focus on symbols of emotional advertising clips, b) concentrate on images of emotional adverting, and c) create self-identification elements. In addition, the empirical results showed that the purchase decision was directly affected by factors of brand recall, brand recognition and perceived quality of product. On the other hand, the factors of kind of media, meaning and form, cultural symbols indirectly affected the purchase decision.
\end{abstract}

Index terms-Emotional marketing, advertising, brand awareness, consumers' perception, purchase decision.

\section{INTRODUCTION}

Growing significance of emotional needs in the consumption environment is conveyed as the basic prerequisite, which naturally calls for defining a new emotional marketing concept. The key assumptions for the formation of the new marketing concept have been tested from the social values aspect characteristic of contemporary society, as values allow identifying the individual's "real" incentives on the market in exchange with the chosen company or with its product brands [1]. Furthermore, emotions have a significant position throughout the span of our lives for the reason that they enhance almost all of our tricky moments by means of any lovely or horrible features [2]. Emotions are considered as a comprehensive experience that consists of the consequent means: behavioral responses, significant results, physiological reactions, and subjective feelings [3].

The process of emotion is known, for instance, how emotions are evoked, can enhance our understanding of what makes us enjoy interacting with any other kind of product. So far, however, little is known about how people respond emotionally to products and what aspects of design or interaction trigger emotional reactions [4].

Manuscript received November 4, 2013; revised January 6, 2014.

Mai Ngoc Khuong and Vu Ngoc Bich Tram are with the School of Business, International University -VNU-HCM, Vietnam (e-mail: mnkhuong@hcmiu.edu.vn, tramvu.iuerd@gmail.com).
Moreover, advertising contain more and more emotional content in order to catch both observer's interest and to correspond to advertising significance [5]. Research and market analysis over the last 10-15 years have revealed that consumers' emotional reaction toward advertisement can be a dominant motivator of spending manners [6], [7] and can significantly convince post experience mind-set and recall [8].

To generate advertising demand more distinctive and consequently, advertisers perhaps use remarkable expressive advertisement-messages intended to generate emotion and make advertisement remembered [9]. The process of these advertisements usually contains high impact stimuli appeals that generate strong emotion. However, companies like health care, insurance, food manufacturers, drug and alcohol use graphic and astounding negative emotional messages, which are used to exploit consumers' fear of cardiac, and cancer [10], 11] has found in his research that emotions play an important role in developing consumer response toward stimuli. Accurately how this works, still, is indecisive. So far, ever more, emotion is perceived as a base sentimental moderator of attitudes and mainly perhaps point of advertising effectiveness [12].

\section{LITERATURE REVIEW}

\section{A. Emotional Marketing}

Emotions represent another form of language universally spoken and understood. An emotion is a mental and physiological state associated with a wide variety of feelings, thoughts, and internal (physical) or external (social) behaviors. Emotion is a process, in which the perception of a set of stimuli, allows a cognitive assessment that enables people to label and identify a particular emotional state [13].

The new concept of marketing, "emotional marketing" concentrate the importance of emotional link between the company and the consumer affected by the system of the characteristic values and needs of contemporary consumers, which, in turn, forms a new symbol consumption culture [1]. Moreover, emotional marketing can be defined as a new paradigmatic approach or a new marketing shift, where management (creation, support, evaluation) of emotional link between the company and the consumer (or other market players) becomes the key exchange-stimulating feature [1]. As the research [1], the theory rests on the basic idea that the consumer's buying/consumption choices are increasingly affected by not rational, but rather emotional attributes of 
goods/services, brand symbols and other exchange elements, whose psycho-symbolic features determine buying/consumption levels, and the type and duration of relationship. Contemporary consumption culture permeated with symbols transforms value creation chains, replacing rationally determined exchange attributes with emotional ones, which serve to stimulate buying or consumption habits using symbols or their created individual socio-emotional experience [1]. To substantiate formation of the emotional marketing concept the paper examines the characteristic value system of the postmodern society, which reveals the emotional basis of those values and forms the "want" (not only needs) of contemporary consumers on the market [1].

The postmodern era faces the lack of "symbolic literacy" [14]-[16], which occurs when consumers do not perceive the sense of things or their basic meaning. As [1] mentioned, symbols have no specific source and can be controlled with the help of the system of signs. In this process the consumer becomes consumer of the symbol/image because this is the way objects are presented to him/her. In this world of symbols/images consumers seek meaning and experiences, whereas creation of images and their transfer to the consumer's consciousness become the basic purpose of emotional marketing. All this supports the importance of emotional attributes in contemporary market exchange, which appear to be the key categories of the emotional marketing concept [1].

\section{B. Consumer Perception}

Perception is the procedures that a person choose, format and interpret stimulation, these stimulation are separated and confirmed to become a person's view of the world. Two persons will never experience the same even to the same thing which is displayed to the same environment. Every day, we are displayed to a millions kinds of stimuli, smells, sound, tastes, sights and textures. But only a small amount of these stimuli are taken in and processed by our brain [17].

\section{Perceived Quality of Product}

Perceive quality in products is complex and it is usually controlled by multi-dimensional constructs, of which measurement requires the designing of valid scale.

Steenkamp [18] defined perceived quality as to indirect between objective product features and consumer orientation, which means consumer check product's quality through some clues due to this perceive quality can be different from each one.

\section{Brand Awareness}

What is the definition of brand? At first, a brand was used to point ownership of cattle [19]. According to reference [20], brands is defined as symbols that consumers are able to identify and distinguish one producer from the others, with the capability to trace a good back to the manufacturer holding it responsible for its quality.

According to Aaker [19], brand awareness indicates the recognition which is communicated onto a brand, which allows consumers to identify with brand product and thus providing companies with unchanged competitive advantage.

Brand awareness influences consumer's capability to identify the brand through specialization. Consumers think about the brand every time they think about the product category. Brand recall and brand recognition identify brand awareness [21]. Brand recall is ability of consumer to recover the brand from memory for a given product category, the category or a purchase or usage situation fulfill the needs as a cue [21].

\section{E. Consumer Purchasing Decision}

According to Consoli [13] mentioned, in a saturated market, the desires are more important than needs and thus the state of mind, the emotions, sympathies become predominant. Besides quality and price, the consumer wants trust, love, dreams (intangible factors).

The emotion becomes more important with the emergence of the principle of the consumer pleasure. Emotions are a distinctive element that must be added to enhance the basis supply of product/service and especially they are designed and managed with rigor and ethical spirit. The consumer doesn't looks for a product/service that meets both the needs and rational processes, but for an object that becomes a center of symbolic meanings, psychological and cultural, a source of feelings, relationships and emotions [13].

Furthermore, the consumer purchasing decisions are defined as the decisions made about purchasing either products or services from a pet retailer [22]. The purchasing decision process of customer interferes between the market strategy and the outcomes. If consumers see a need that its product may provide, be aware of the products and its abilities, decide that it is the best available solution, proceed to purchase it, and become satisfied with the result of the purchase, that is the way that the firm can succeed [23].

Therefore, as Rytel [1] defined, emotional marketing can be interpreted as a unique shift in marketing management which focus on the emotional creation of relationships between the company and the consumer as the key motivating factor for consumers' buying or consumption decisions and exchange. All this conveys a postmodern method to the science of marketing at which buying or consumption models are built up in emotional categories with focus on symbols and their created visions, images and sensations. When consumers' buying or consumption process is stimulated with psycho-symbolic attributes of exchange and exchanged objects, they all become the significant feature of the postmodern era [1]. With the mentioned above independent and dependent variables related to the repurchase intention, this study hypothesizes that:

- $\mathrm{H}_{1}$ : The factors of emotional marketing positively affect consumers' brand recall.

- $\mathrm{H}_{2}$ : The factors of emotional marketing positively affect consumers' brand recognition.

- $\mathrm{H}_{3}$ : The factors of emotional marketing positively affect consumers' perception of product.

- $\mathrm{H}_{4}$ : The factors of emotional marketing positively affect consumers' product perceived quality.

- $\mathrm{H}_{5}$ : The factors of emotional marketing positively affect consumers' purchase decision.

- $\mathrm{H}_{6}$ : The factors of brand awareness (brand recall and brand recognition) and consumers' perception (perception and perceived quality of product) positively 
affect consumers' purchase decision.

- $\mathrm{H}_{7}$ : Consumers' purchase decision is hypothesized to be indirectly affected by customer perception, brand awareness, and the factors of emotional marketing program.

\section{Methodology}

\section{A. Questionnaire Design and Data Collection}

This study mainly focuses on consumer's purchase decision. Therefore, the quantitative approach was the major method applied to this study. This means that the research based on a questionnaire survey in which data were collected from sample selected from the target population. Most of measures were based on a five point Likert scale in which 1 is "strongly disagree" and 5 is "strongly agree" and for the third question of the questionnaire "how often do you watch emotional advertising clips of the products", 1 is "not at all" and 5 "very often".

Target population of this study was consumers who used the products of Neptune oil or OMO washing powder or Kotex tampon or Gau Đo noodle. Based on literature review, questionnaire was designed and directly sent to consumers who often used the products of these four companies. This study considered only consumers who often used the products mentioned in the emotional advertising clips would have enough perceptive ability to answer all questions without any outside influence.

Data Collection: Convenience sampling method was used to collect data. The questionnaire survey was conducted by two ways; online and offline. Questionnaires were directly given to respondents at: universities, company gates, and supermarkets. In addition, online questionnaire link was also sent to respondents through email and Facebook to reach the final sample size of 197 cases.

\section{B. Factor Analysis and Reliability}

Two factors analyses used the principal component extraction method and varimax rotation of 28 items of the group of dependent variables and 25 items of the group of independent variables related to the factors affecting the purchase decision, were conducted on the sample of 197 consumers of Neptune oil, OMO washing powder, Kotex tampon, and Red Bear noodle. Previous to running the analysis with the SPSS, the data was screened by examining the descriptive statistics on each item. For this study, the factor analysis procedure was applied twice; once for the group of dependent variables, including five variables, and again for the other group of independent variables, including 8 variables. The Kaiser-Meyer-Olkin measure of sampling adequacy was .848 for the group of dependent variables and .832 for the group of independent variables (according to Pallant [24] to be significant, the value has to be .60 or above), indicating that the present data was suitable for principal components analysis. Similarly, Bartlett's test of sphericity [25] was significant $(p<0.001)$, indicating sufficient correlation between the variables to proceed with the analysis.
TABLE I: SUMMARY OF DEPENDENT VARIABLES WITH RELIABILITY COEFFICIENTS

\begin{tabular}{lcc}
\hline Given Names & $\begin{array}{l}\text { Number of } \\
\text { Items }\end{array}$ & Alpha \\
\hline 1. Product Perception (PROPER) & 5 & 0.811 \\
\hline 2. Perceived Product Quality (PERQUA) & 4 & 0.827 \\
\hline 3. Brand Recognition (BRACO) & 4 & 0.699 \\
\hline 4. Purchase Decision ( PURDE) & 3 & 0.711 \\
\hline 5. Brand Recall (BRACA) & 3 & 0.586 \\
\hline
\end{tabular}

Using the Kaiser-Guttman's retention criterion of Eigenvalues greater than 1.0, a five-factor solution provided the clearest extraction for the group of dependent variables, including 28 items. The five factors accounted for $59.8 \%$ of the total variance and the Cronbach's coefficients ranged from .586 to .811 among the factors, indicating good subscale reliability as shown in Table I. In addition, an eight factors solution was conducted for the group of independent variables consisting of 25 items. These eight factors accounted for $59.7 \%$ of the total variance. The Cronbach's coefficients ranged from .671 to .759 among the eight factors indicating good subscale reliability as shown in Table II.

TABLE II: SUMMARY OF INDEPENDENT VARIABLES WITH RELIABILITY COEFFICIENTS

\begin{tabular}{lcc}
\hline \multicolumn{1}{c}{ Given Names } & $\begin{array}{c}\text { Number of } \\
\text { Items }\end{array}$ & Alpha \\
\hline 1. Meaning and Form (MEFO) & 5 & 0.759 \\
\hline 2. Emotional Traits (EMTRA) & 4 & 0.747 \\
\hline 3. Cultural Symbols (CUSY) & 4 & 0.797 \\
\hline 4. Image (IMAGE) & 3 & 0.716 \\
\hline 5. Kinds of Advertisement (KINAD) & 3 & 0.754 \\
\hline 6. Symbols (SYBO) & 2 & 0.638 \\
\hline 7. Self-Identification (SEFIDE) & 2 & 0.671 \\
\hline
\end{tabular}

The present five factor model and eight factor model of this study were deemed the best solution because of their conceptual clarity and ease of interpretability.

\section{RESULTS}

\section{A. Profile of Consumer Involved in the Study}

The profiles of consumers involved in the study are shown in Table III.

\section{B. Factors affecting Purchase Decision}

In order to find out which factors had relationship with the dependent variable of the purchase decision, Pearson Product-moment Correlation Coefficients (r) were employed. Table IV shows that there were positive significant relationships between the dependent variable of PURDE and the independent variables: MEFO $(r=0.289, p<0.001)$, EMTRA $(r=0.236, p<0.001)$, CUSY $(r=0.282, p<0.001))$, $\operatorname{IMAGE}(r=0.359, p<0.001))$, KINAD $(r=0.208, p<0.001))$, SYBO $(r=0.356, p<0.001))$, SEFIDE $(r=0.331, p<0.001)$. This means that better MEFO, EMTRA, CUSY, IMAGE, KINAD, SYBO and SEFIDE could lead to higher purchase decision. 
In conclusion, the PURDE was moderately correlated with the emotional marketing as shown in the correlation coefficients and significant levels in Table IV.

TABLE III: CONSUMER PROFILES $(N=197)$

\begin{tabular}{|c|c|c|}
\hline & Frequency & Percentage \\
\hline \multicolumn{3}{|l|}{$\overline{\text { Gender }}$} \\
\hline - Male & 67 & 34.0 \\
\hline - Female & 130 & 66.0 \\
\hline Total & 197 & 100.0 \\
\hline \multicolumn{3}{|l|}{ Relationship status } \\
\hline - Single & 194 & 98.5 \\
\hline - Married & 3 & 1.5 \\
\hline Total & 197 & 100.0 \\
\hline \multicolumn{3}{|l|}{$\overline{\text { Age }}$} \\
\hline - 18-25 years old & 186 & 94.4 \\
\hline - 26-35 years old & 9 & 4.6 \\
\hline - 36-45 years old & 1 & 0.5 \\
\hline - 46-55 years old & 0 & 0.0 \\
\hline - Above 55 years old & 1 & 0.5 \\
\hline Total & 197 & 100.0 \\
\hline \multicolumn{3}{|l|}{ Educational Level } \\
\hline - High School & 3 & 1.5 \\
\hline - Vocational Level & 0 & 0.0 \\
\hline - College & 7 & 3.6 \\
\hline - Graduated & 183 & 92.9 \\
\hline - Master & 4 & 2.0 \\
\hline Total & 197 & 100.0 \\
\hline \multicolumn{3}{|l|}{ Income } \\
\hline - Below 5 million VND & 162 & 83.2 \\
\hline - 5-10 million VND & 23 & 11.7 \\
\hline - 10-15 million VND & 8 & 4.1 \\
\hline - 15-20 million VND & 0 & 0.0 \\
\hline - Above 20 million VND & 2 & 1.0 \\
\hline Total & 197 & 100.0 \\
\hline
\end{tabular}

TABLE IV: CORRELATIONS BETWEEN VARIABLES

\begin{tabular}{|c|c|c|c|c|c|c|c|}
\hline & PURDE & 1 & 2 & 3 & 4 & 5 & 6 \\
\hline 1. MEFO & $0.289^{* *}$ & & & & & & \\
\hline 2. EMTRA & $0.236^{* *}$ & $0.520^{* * *}$ & & & & & \\
\hline 3. CUSY & $0.282^{* * *}$ & $0.444^{* *}$ & $0.503^{* *}$ & & & & \\
\hline 4. IMAGE & $0.359^{* *}$ & $0.376^{* *}$ & $0.471^{* *}$ & $0.472^{* *}$ & & & \\
\hline 5. KINAD & $0.208^{* *}$ & 0.100 & 0.044 & 0.045 & 0.085 & & \\
\hline 6. SYBO & $0.356^{* *}$ & $0.199^{* *}$ & $0.187^{* *}$ & $0.221^{* * *}$ & $0.274^{* *}$ & $0.216^{* *}$ & \\
\hline 7. SEFIDE & $0.331^{\text {** }}$ & $0.221^{\text {** }}$ & $0.355^{\text {** }}$ & $0.336^{* * *}$ & $0.374^{* *}$ & 0.091 & $0.275^{* *}$ \\
\hline Mean & 3.51 & 3.86 & 3.94 & 3.78 & 3.65 & 2.14 & 3.40 \\
\hline SD. & 0.593 & 0.592 & 0.605 & 0.583 & 0.690 & 0.838 & 0.717 \\
\hline
\end{tabular}

**. Correlation is significant at the 0.001 .

TABLE V: CORRELATIONS BETWEEN PROPER, PERQUA, BRACO, BRACA AND PURDE

\begin{tabular}{ccccc}
\multicolumn{5}{c}{ BRACA AND PURDE } \\
\hline & PURDE & 1 & 2 & 3 \\
\hline 1. PROPER & $0.378^{* *}$ & & & \\
2. PERQUA & $0.458^{* *}$ & $0.434^{* *}$ & & \\
3. BRACO & $0.480^{* *}$ & $0.512^{* *}$ & $0.517^{* *}$ & \\
4. BRACA & $0.356^{* *}$ & $0.306^{* *}$ & $0.254^{* *}$ & $0.446^{* *}$ \\
\hline Mean & $\mathbf{3 . 5 1}$ & $\mathbf{3 . 7 6}$ & $\mathbf{3 . 3 3}$ & $\mathbf{3 . 6 1}$ \\
\hline SD & $\mathbf{0 . 5 9 3}$ & $\mathbf{0 . 5 4 6}$ & $\mathbf{0 . 6 1 8}$ & $\mathbf{0 . 5 1 8}$ \\
\hline
\end{tabular}

Table $\mathrm{V}$ shows that there were also positive significant relationships between the dependent variable of PURDE and the independent variables: BRACA $(r=0.356, p<0.001)$ and PROPER $(r=0.378, p<0.001)$, PERQUA $(r=0.458, p<0.001)$, $\operatorname{BRACO}(r=0.480, p<0.001)$. This indicates that a high level of brand recall, brand recognition, perception and perceived quality of product were associated with a high level of purchase decision.

In general, the PURDE was positively correlated with the BRACA, BRACO, PROPER and PERQUA, as shown in Table V.

The total effect of one variable on PURDE could be divided into direct effects and indirect effects. The direct effect of an independent variable on the dependent variable of PURDE was the standardized regression coefficient $(\beta)$ and was considered as the path coefficient in the path model. The indirect effect of an independent variable on the dependent variable through the intervening variables was the total product of the effects of that independent variable on the intervening variables and the effects of the intervening variables on the dependent variable.

\section{Path Diagram of Purchase Decision}

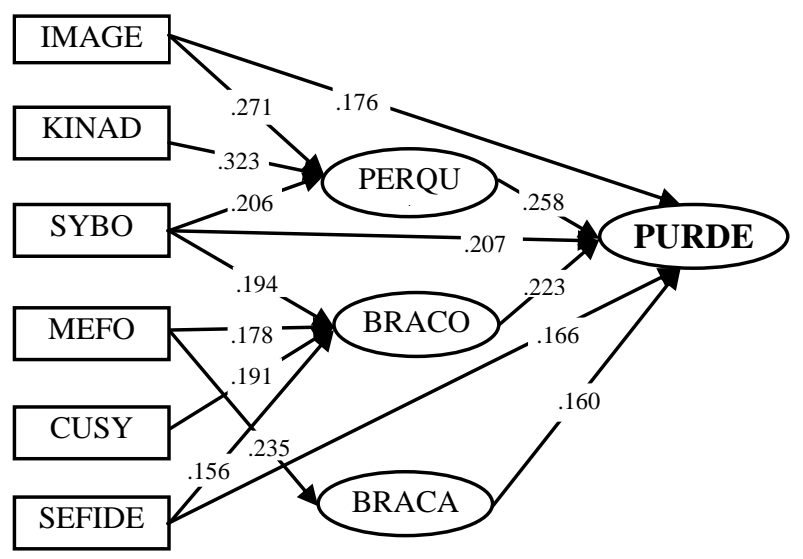

Fig. 1. Standardized coefficients of PURDE model

\section{Indirect Effects of the Purchase Decision \\ 1) Product perception and purchase decision}

A series of six multiple regression analyses were conducted to test the hypotheses about "the direct and indirect effects of emotional marketing on brand recall, brand recognition, product perception, perceived quality, and purchase decision". From the hypothesis $\left(H_{1}\right)$ testing results, it was concluded that only factor of image have direct effects on consumers' product perception with $(\beta=0.257, p<0.001)$. However, the results show that there was no direct effect of the product perception on purchase decision. This means that through the intervening variable of product perception, none of the independent variables of emotional marketing created an indirect effect on purchase decision.

\section{2) Perceived quality and purchase decision}

Hypothesis 2 was tested and the results show that perceived quality of product was mainly affected by important predictor: image $(\beta=0.271, p<0.01)$, kinds of advertisement $(\beta=0.323, p<0.01)$ and symbols $(\beta=0.206$, $p<0.01)$. These three factors directly affected the intervening variable of product perceived quality and then product perceived quality directly caused an effect on purchase decision with $(\beta=0.258, p<0.01)$. Consequently, through the intervening variable of perceived quality of product, the factors of image, kind of advertisement, and symbols created 
indirect effects on purchase decision. Thus, this study suggests that better image, kind of advertisement, and symbols will lead to better consumers' product perceived quality and purchase decision.

\section{3) Brand recognition and purchase decision}

Hypothesis 3 was tested and the results show that brand recognition was mainly affected by four important predictors: symbols $(\beta=0.194, p<0.01)$, meaning and form $(\beta=0.178$, $p<0.01)$, cultural symbols $\quad(\beta=0.156, \quad p<0.01) \quad$ and self-identification $(\beta=0.191, p<0.01)$. These four factors directly affected the intervening variable of brand recognition and then brand recognition directly caused an effect on purchase decision with $(\beta=0.223, p<0.01)$. Consequently, through the intervening variable of brand recognition, the factors of symbols, cultural symbols, self-identification and meaning and form created indirect effects on purchase decision. Thus this study suggests that as a high level of symbols, cultural symbols, self-identification and meaning and form become apparent, the brand recognition and purchase decision are likely to be greater.

\section{4) Brand recall and purchase decision}

Hypothesis 4 was tested and the results show that brand recall was mainly affected by important predictor: meaning and form $(\beta=0.235, p<0.01)$. This factor directly affected the intervening variable of brand recall and then brand recall directly caused an effect on purchase decision with $(\beta=0.160$, $p<0.01)$. Consequently, through the intervening variable of brand recall, the factor of meaning and form created indirect effects on purchase decision. Thus, this study suggests that as a high level meaning and form become apparent, the brand recall and purchase decision are likely to be greater. Through the above sections, hypothesis 6 has also been simultaneously discussed and reported.

\section{5) Emotional marketing and purchase decision}

Hypothesis 5 was tested and the results show that purchase decision was mainly affected by image $(\beta=0.176, p<0.01)$, symbol $(\beta=0.207, p<0.01)$, and self-identification $(\beta=0.166$, $p<0.01)$. Thus this study suggests that better image, symbol, and self-identification of the emotional marketing will lead to higher level of purchase decision.

\section{E. Total Causal Effects of the Purchase Decision}

Table VI summarizes the total, direct, and indirect effects of the independent variables on PURDE (Hypothesis 7). Regarding the total effects, the factor of symbols in emotional marketing had the strongest impact on PURDE $(\beta=0.303)$, followed by the factor of perception of quality product $(\beta=0.258)$, the factor of image in the emotional marketing $(\beta=0.246)$, then the factor of brand recognition $(\beta=0.223)$, the factor of self-identification in emotional marketing $(\beta=0.209)$, the factor of brand recall of purchase decision $(\beta=0.160)$, the factor of kind of media in emotional marketing $(\beta=0.083)$, the factor of meaning and form in emotional marketing $(\beta=0.077)$. In addition, the factors of cultural symbols provided smallest impact on purchase decision with $(\beta=0.035)$. The total effect of the factors affecting purchase decision was 1.594 in which direct effects from factors of IMAGE, SYBO, SEFIDE, PERQUA, BRACO, BRACA account for $75 \%$, while indirect effects account for $25 \%$.

TABLE VI: DIRECT, INDIRECT AND TOTAL CAUSAL EFFECT

\begin{tabular}{lccc}
\hline \multirow{2}{*}{ Variables } & \multicolumn{3}{c}{ Causal Effects } \\
\cline { 2 - 4 } & Direct & Indirect & Total \\
\hline IMAGE & 0.176 & 0.070 & 0.246 \\
KINAD & --- & 0.083 & 0.083 \\
SYBO & 0.207 & 0.096 & 0.303 \\
MEFO & --- & 0.077 & 0.077 \\
CUSY & --- & 0.035 & 0.035 \\
SEFIDE & 0.166 & 0.043 & 0.209 \\
PERQUA & 0.258 & --- & 0.258 \\
BRACO & 0.223 & --- & 0.223 \\
BRACA & 0.160 & --- & 0.160 \\
\hline \multicolumn{1}{c}{ TOTAL } & $\mathbf{1 . 1 9 0}$ & $\mathbf{0 . 4 0 4}$ & $\mathbf{1 . 5 9 4}$ \\
\hline
\end{tabular}

The results of this study shows that factors of emotional marketing do not only significantly affect customers' purchase decision, but also have important implications for increasing brand awareness and consumers' perception of product. In summary, the implications of the results also emphasize to identify the determinants of purchase decision. Understanding the main factors influence brand awareness, consumers' perception and purchase decision and concentrate to develop them.

\section{DISCUSSIONS AND IMPLICATIONS}

\section{A. Practical Implication and Contributions to Marketing}

The practical implications to be drawn from this study have to do with the manner in which marketing managers of the products like OMO, Neptune, Kotex, Red Bear should notice in the future. First, the findings of this study, based on significant correlations between the independent and dependent variables, suggest that in order to have consumers' purchase decision, the companies should: a) pay intention on emotional marketing especially images, symbols, self-identification for each advertising to make it more truthful, unique, humane value, etc., b) concentrate on kinds of media as Internet and social media which is quickly effective communicability to consumers, c) mention in human meaning and form related to Eastern culture to connect relationship with consumers closely.

Raising consumers' purchase decision should interpret more consumers' perception as perception and perceived quality of product and more brand awareness as brand recall and brand recognition.

The results of this study also showed that there were significant correlations between brand recognition and independent variables. Consequently, in order to have significant brand recognition in brand awareness, this study suggests that marketing manager of the companies should pay attention and focus on emotional marketing. Moreover, marketing manager has to consider the four main elements affecting the brand recognition. They are symbols, meaning 
and form, cultural symbols and self-identification. These four factors have a significant effect on brand recognition in brand awareness.

The brand recall in brand awareness was found to be one of reasons why the companies design to identify in purchase decision. This study found that there were significant correlations between the factor of brand recall in brand awareness and the independent variables. It was argued that in order to obtain the brand recall, the companies also should concentrate on meaning and form of emotional marketing. Differing from brand recognition, the brand recognition has only the main effects as meaning and form. When marketing managers consider improving the brand recall in brand awareness as well as purchase decision, they should depend on meaning and form of emotional marketing.

This study also finds that the perceived quality of product was one of considerations that marketing managers of the companies believe may lead to purchase decision. The results showed there were significant relationships between the perceived quality of product and the independent variables. Thus, this study suggests that in order to achieve perceived quality of product, the companies should identify emotional marketing. However, marketing manager has to consider the three main elements affecting the perception of product. They are image, kind of media, and symbols of emotional marketing. These three factors have a significant effect on perceived quality of product in consumers' perception as well as purchase decision.

The perception of product was found to be one of reasons why the products like OMO, Neptune, Kotex, Red Bear designs to identify in purchase decision. This study found that there were significant correlations between the factor of perception of product and the independent variables. It was argued that in order to obtain the perception of product, the Companies also should focus on emotional marketing. The perceived quality of product has the main effects as image. When marketing managers consider improving the perceived quality of product as well as purchase decision, they should depend on image first.

Finally, in order to achieve a high level of purchase decision when the companies decides to improve it, the marketing manager should pay greatly attention and consideration to the important factors that provide significantly unique contributions to predicting purchase decision directly and indirectly, as suggested by this study. The significant determinants that marketing manager of the companies should assign priority to emotional marketing are meaning and form, cultural symbols, image, kinds of advertisement, symbol, and self-identification of advertising clips. In addition, this study also found that brand recall, brand recognition and perceived quality of product were the main aspects that the products like OMO, Neptune, Kotex, Red Bear expected to obtain and that the emotional marketing directly affected consumers' evaluation of purchase decision.

\section{B. Applied Implications}

Through conducting this specific study, a review of a wide range of literature in the field of management studies was conducted, especially in the field of marketing. In addition, the application of purchase decision model to practice in the marketing industry with empirical research and hypothesis testing was the contribution of this study to assert the firmness of purchase decision and at least to initially making it more applicable in the field of marketing.

\section{CONCLUSION}

All the objectives of this study have been successfully obtained: firstly to identify what factors of emotional marketing affect consumers' purchase decision through consumer's product perception and brand awareness; secondly to measure direct and indirect effects of independent variables (meaning and form, image, symbol, self-identification, emotional traits, kind of media, cultural symbols) on dependent variable of purchase decision through brand awareness and consumers' perception; and thirdly provide recommendations for improving emotional marketing and how to increase consumer's brand awareness, product perception, and purchase decision.

The application of the multivariate statistical techniques with factor analysis, standard multiple regression analyses, and path analysis allows the exertion of a causal relationship between the exogenous and endogenous variables of the consumers' purchase decision model. Explanations and suggestions given were based on the review of the literature and the empirical findings of the study. In terms of significant relationships, bivariate correlations and Pearson product-moment correlation coefficients were employed to explore the relationship and its strength between each independent variable and the purchase decision, as well as between each intervening variable and the dependent variable of the study. The direct and indirect effects of purchase decision were discussed and explained in order to obtain clear answers and evidence for all research hypotheses. Thus, the implications of this study provide both theoretical and practical contributions to the field of marketing management and development.

Although this study can be considered an initiation into measuring the purchase decision through intervening variables, the results of this study showed that not all factors have direct and indirect effects on the purchase decision for several subjective and objective reasons. Future research should apply the model in other contexts with more meaningful statements for each factor or determinants of purchase decision.

This study argued that in order to purchase decision, the companies of products like OMO, Neptune, Kotex, Red Bear should have a high level of emotional marketing, especially symbols, images and self-identification in Ho Chi Minh in particularly and in Vietnam market in generally. In addition, this study also found that the factors of brand recall, brand recognition and perception of product were the main purposes and motivations of improving the purchase decision. These factors directly influenced the purchase decision. On the other hand, the factors of kinds of media, meaning and form, cultural symbols did not directly affect purchase decision, but indirectly effects on purchase decision through perceived quality of product, brand recognition of brand awareness in purchase decision, respectively. 


\section{REFERENCES}

[1] T. Rytel, "Emotional marketing concept: The new marketing shift in the postmodern era," Business: Theory and Practice, vol. 11, no. 1, pp. 30-38, November 2009.

[2] J. T. Larsen, A. P. McGraw, and J. T. Cacioppo, "Can people feel happy and sad at the same time," Journal of Personality and Social Psychology, vol. 81, no. 4, pp. 684-696, October 2001.

[3] P. M. A. Desmet, "Measuring emotions development and application of an instrument to measure emotional responses to products," Journal of Advertising Research, vol. 46, no. 4, pp. 410-419, 2003.

[4] P. U. Majumdar. (November 2012). Emotional marketing-chasing the "share of heart" of your prospective customers. Asia Pacific Journal of Marketing \& Management Review. [Online]. 1(3). pp. 68-69. Available: www.indianresearchjournals.com

[5] R. L. Hazlett and S. Y. Hazlett, "Emotional response to television commercials: facial EMG vs. self-report," Journal of Advertising Research, vol. 39, no. 2, pp. 7-23, April 1999.

[6] C. T. Allen, K. A. Machleit, and S. S. Kleine. (March 1992). A Comparison of Attitude and Emotion as Predictors of Behavior at Diverse Level of Behavior Experience. Journal of Consumer Research. [Online]. 18(3). pp. 493-504. Available: http://www.journals.uchicago.edu/JCR/

[7] R. I. Haley and A. L. Balidinger. (November 2000). The ARF Copy Research Validity Project. Journal of Advertising research. [Online]. 40(6). pp. 114-135. Available http://journals.cambridge.org/jid_JAR

[8] C. Park and Ethorson, "Influence on emotional response to commercials different executional styles in emotion in advertising: theoretical and practical exploration," S. Agres, J. A .Edell, and T. M Dubistsky (Eds), west port: Quorm books, Patients, pp. 22-26, 1990.

[9] D. J. Moore, "Advertising that makes the brain itch," Journal of Consumer Research, vol. 22, no. 4, pp. 124-144, 1989.

[10] R. Alsop, "Drug and alcohol clinics vie for patients," Wall Street Journal, vol. 39, no. 2, pp. 219-230, 1988.

[11] L. A. Marsha, "Measuring emotions in the consumption experience," The Journal of Consumer Research, vol. 24, no. 2, pp. 127-146, September 1997.

[12] T. A. Shimp, "Attitude toward the AD as a mediator of consumer brand choice," Journal of Advertising, vol. 10, no. 2, pp. 9-15, June 1981.

[13] D. Consoli, "A new concept of marketing: the emotional marketing," Broad Research in Accounting, Negotiation, and Distribution, BRAND, vol. 1, no. 1, pp. 52-59, 2010.

[14] A. F. Firat, "The consumer in a postmodernity," Advances in Consumer Research, vol. 18, pp. 70-76, 1991.

[15] A. F. Firat, N. Dholakia, and A. Venkatesh, "Marketing in a postmodern world," European Journal of Marketing, vol. 29, no. 1, pp. 40-56, 1995.

[16] A. F. Firat and A. Venkatesh, "Libratory postmodernism and the reenchantment of consumption," Journal of Consumer Research, vol. 22, no. 3, pp. 239-267, 1995.

[17] M. R. Solomon, G. Bamossy, S. Askegaard, and M. K. Hogg, Consumer Behaviour: A European Perspective, 4th ed. Harlow: Prentice Hall, 2009.

[18] J. B. E. M. Steenkamp, "Conceptual model of the quality perception process," Journal of Business Research, vol. 21, pp. 309-333, December 1990.

[19] D. A. Aaker, Strategic Market Management; New York: John Wiley \& Sons, 2005, pp. 356.

[20] S. Koehn, "Negotiating candidacy: access to care for ethnic minority seniors," Ageing and Society, vol. 29, no. 4, pp. 585-608, 2009.

[21] K. L. Keller, "Building customer-based brand equity: A blueprint for creating strong brands," Marketing Management, 2001, pp. 15-19.

[22] T. Chaipradermsak, "The influential factors on consumers' purchasing decision in Bangkok pet retailing business," M. B. A thesis, Dept. Management, Shinawatra Univ., Bangkok, Thailand, 2007.

[23] D. I. Hawkins, R. J. Best, and K. A. Coney, Consumer Behavior: Building Marketing Strategy, 8th ed. Boston: McGraw-Hill, 2001.

[24] J. Pallant, SPSS Survival Manual: A Step by Step Guide to Data Analysis Using SPS, 12th ed. Maidenhead, Berkshire: Open University Press, 2005.

[25] M. S. Bartlett, "A note on multiplying factors for various chi-squared approximations," Journal of the Royal Statistical Society, Series, vol. 16, pp. 296-298, 1954.

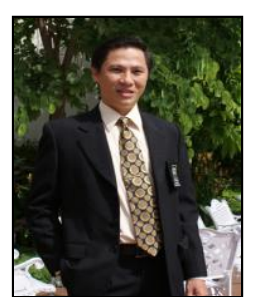

Thailand.

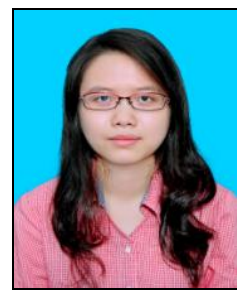

Mai Ngoc Khuong is a lecturer and researcher of School of Business Administration - International University - VNU-HCM. He has bachelor degree in Tourism and Hospitality Management, Master of Science degree in Leisure, Tourism and Environment at Wageningen University - The Netherlands, and $\mathrm{PhD}$ degree in Development Management at School of Public Administration of the National Institute of Development Administration (NIDA), Bangkok -

Vu Ngoc Bich Tram is a research assistant of School of Business Administration - International University - Vietnam National University - Ho Chi Minh. 